RESEARCH ARTICLE

\title{
Multidrug Resistant Bacterial Pathogens in the Indoor Air and Floors of Surgical Wards in a University Hospital
}

\author{
Ahmed Olowo-Okere ${ }^{1}$, YKE Ibrahim², M Babandina ${ }^{3}$, BO Olayinka ${ }^{2}$ \\ ${ }^{1}$ Department of Pharmaceutics and Pharmaceutical Microbiology, Usmanu Danfodiyo University, Sokoto, Nigeria \\ ${ }^{2}$ Department of Pharmaceutics and Pharmaceutical Microbiology, Ahmadu Bello University, Zaria, Nigeria \\ ${ }^{3}$ Department of Microbiology and Parasitology, University of Abuja Teaching Hospital, Gwagwalada, Abuja, Nigeria
}

\begin{abstract}
Objective: The hospital environment is a major source of nosocomial pathogens. These pathogens could contaminate and colonize surgical wounds leading to infections. This study evaluated the bacteriological quality of air and floors of surgical wards of a University Teaching Hospital in Abuja, Nigeria.
\end{abstract}

Methods: Bacteriological quality of air and floor of surgical wards of the hospital was evaluated using passive air sampling and swabbing methods respectively. The isolates were characterized using rapid test kits and antibiotic susceptibility was determined by the modified Kirby-Bauer disc diffusion method.

Results: A total of 121 bacterial isolates comprising eleven species were isolated. In the air and floor of all the surgical wards, Staphylococcus spp. (>42\%) was the most prevalent Gram-positive bacterium followed by Bacillus subtilis (20.4\%). Among the Gram-negative bacterial isolates, Pseudomonas aeruginosa (13.0\%) and Proteus mirabilis (9.0\%) were the most prevalent in the air and floor, with occasional detection of Acinetobacter baumannii and other members of the Enterobacteriaceae family. The bacterial isolates exhibited diverse degrees of susceptibility to the commonly prescribed antibiotics. The isolated bacteria were mostly sensitive to fluoroquinolones.

Conclusion: This study documented the diverse environmental microbiota of the surgical wards of the hospital. The high resistance of the isolated bacteria to the commonly prescribed antibiotics in the hospital highlighted the need for improved infection control and patient safety protocols in the hospital so as to mitigate the spread of nosocomial infections in the surgical wards of the hospital. J Microbiol Infect Dis 2018; 8(3):108-113

Keywords: Microbial quality, Hospital environment, Indoor air, Antibiotics, Multidrug resistance

\section{INTRODUCTION}

The hospital environment is a major source of nosocomial pathogens. These pathogens could contaminate and colonize surgical wounds leading to infections. These infections otherwise known as the surgical site infections (SSIs) have been shown to increase duration of stay in the hospital by up to 9.7 days, raise cost of treatment due to additional tests and therapeutic antibiotic treatment. It may also lead to additional surgery with accompanied morbidity which can occasionally be permanent and sometimes mortality [1-3].

The exogenous sources of SSI pathogens include surgical personnel (especially members of the surgical team), the operating room environment (including air), tools, instruments, and materials brought to the sterile field during an operation [4-6]. In a health care facility, various items (animate and inanimate) can harbor infectious agents and can serve as a vehicle for transmission of nosocomial infection [7]. This is further exacerbated by the ability of some microorganisms to persist for a long period on surfaces through biofilm formation and the ability of some of the organisms to resist cleaning and disinfection [8]. Frequent contamination of operating theatre air, floor, foot wears, and protective wears by pathogenic bacteria has been reported [8-10]. Dispersal of these pathogens into surgical wards and

Correspondence: Dr. Ahmed Olowo-Okere, Department of Pharmaceutics and Pharmaceutical Microbiology, Usmanu Danfodiyo University, Sokoto, Nigeria

Email: olowookere.ahmed@udusok.edu.ng

Received: 15 March 2017 Accepted: 19 July 2018

Copyright (C JMID / Journal of Microbiology and Infectious Diseases 2018, All rights reserved 
operating theatre air and eventual contamination of sterile tissue could result in life threatening infections [11]. Similarly, the use of mobile phones in clinical sensitive areas has also been demonstrated to contribute to the spread of infectious agents in the hospital $[4,12,13]$. Thus, the use of any item in patient care should be weighed against the risk of contamination and transmission of infectious agents.

Etiological agents involved in SSI vary from one study to another depending on the geographical location, procedures, surgeons, hospital or even wards within hospital. The compromised immunity of surgical patients and the invasive techniques used during surgical procedures make the patients highly susceptible to colonization and infections. Thus, there is need to determine the nature and susceptibility pattern of bacterial isolates from the indoor air and floor of surgical wards. This study therefore aimed to evaluates the bacteriological quality of indoor air and floor of the surgical wards of a University Teaching Hospital in Abuja, Nigeria.

\section{METHODS}

\section{Study area}

This descriptive study was conducted at three surgical service units of University of Abuja Teaching Hospital (UATH), Gwagwalada, Abuja. The hospital (UATH) is a 500 beds capacity tertiary care facility providing essential medical and surgical services to over three million residents of the Federal Capital Territory and referral cases from adjoining states of Niger, Kogi, Nasarawa and Benue.

\section{Study design}

The study was conducted between December, 2014 and March, 2015, in the three surgical wards of the University of Abuja Teaching Hospital, Abuja. The units are the male, female and pediatric surgical wards. Samples were collected from the air and floors of the wards. The proposal for this study was approved by the research and ethics committee of the hospital (FCT/UATH/HREC/PR/389).

\section{Sampling and Isolation of Bacteria}

The bacteriological study of the air and floor of the surgical wards was done using settling plate (passive air sampling) and swabbing methods respectively. This was done between 10:00 and
11:00 am when activities were at its peak in the hospital, twice a week (Mondays and Thursdays) for the duration of the study.

For the air of the wards, $90 \mathrm{~mm}$ plates containing sterile Nutrient agar (Oxoid Ltd., UK) were placed at different areas of the wards, $1 \mathrm{~m}$ away from the walls, $1 \mathrm{~m}$ above the ground and left uncovered for one hour, twice a week for the duration of the study as previously described [14]. Thereafter, the plates were covered and immediately taken to the Medical Laboratory Department of the hospital for incubation aerobically at $37^{\circ} \mathrm{C}$ for $18-24$ hours.

For the floors of surgical wards where surgical patients were being kept during recovery before discharge, randomly selected area of the floor (one meter square) already subdivided into 16 sub-squares were swabbed using sterile cotton wool swab moistened with sterile normal saline. The swabs were then inoculated into a test tube containing $9 \mathrm{ml}$ sterile normal saline and mixed properly so as to discharge its contents. One milliliter $(1 \mathrm{ml})$ each of this mixture was then used to flood plates of Nutrient agar in duplicates and thereafter incubated aerobically at $37{ }^{\circ} \mathrm{C}$ for $18-24$ hours as previously described [8].

\section{Isolate characterisation and bacterial identification}

Well separated and morphologically distinct colonies that developed after series of subculturing in Mannitol salt and MacConkey agar were selected, isolated, purified into pure cultures and were characterized by their Gram staining reactions into Gram positive or Gramnegative cocci/bacilli. Biochemical identification and speciation was done using Microgen GN-ID $\mathrm{A}+\mathrm{B}, \mathrm{GN}-\mathrm{Staph}$ and GN-Bacillus kits (Microgen, Camberley, United Kingdom).

The test was performed according to the manufacturer's specifications. Briefly, saline suspension of the test organisms was added into wells of the kit and wells 1, 2, 3 and 9 were overlaid with sterile paraffin oil. After overnight (18-24 hours) incubation at $37{ }^{\circ} \mathrm{C}$, suitable reagents (such as Nitrate $A$ and $B$, Kovacs, Tryptophan deaminase (TDA), Voges-Proskauer (VPI and II) were added to wells 8, 10 and 12 for additional tests and color changes of the different tests were recorded. The results were 
converted into four to eight digits codes depending on the organisms being tested and interpreted using the Microgen Identification Software Package.

\section{Antimicrobial Susceptibility Test}

Antibiotic susceptibility test was done on Mueller-Hinton agar (Oxoid, UK) using the modified Kirby-Bauer disc diffusion method as outlined in the guidelines from Clinical and Laboratory Standards Institute [15]. The following commercially prepared antibiotic discs (Oxoid, UK) selected based on antibiotics prescription pattern in the hospital were used: ciprofloxacin $(30 \mu \mathrm{g})$, amoxicillin $(10 \mu \mathrm{g})$, cephalexin $(30 \mu \mathrm{g})$, amoxicillin-clavulanate $(20 / 10 \mu \mathrm{g})$, gentamicin $(10 \mu \mathrm{g})$, ceftriaxone (30 $\mu \mathrm{g})$, levofloxacin $(30 \mu \mathrm{g})$, cefuroxime $(30 \mu \mathrm{g})$ and ampicillin $(10 \mu \mathrm{g})$. Clear zone diameters were measured to the nearest millimeter using a millimeter ruler under natural light and interpreted based on the recommended breakpoints [15].

\section{Data Analysis}

Data collected was analysed using the GraphPad Prism®, version 7.0. (GraphPad Software Inc., CA, USA). Descriptive statistical including frequencies and percentages were used in the analyses.

\section{RESULTS}

Overall, 121 bacterial isolate comprising eleven species were isolated from the 144 specimens collected from the three wards of the hospital. From the air, 67 (55.4\%) and floor 54 (44.6\%) bacterial isolates were isolated. In all the wards, Staphylococcus spp. were most prevalent bacteria followed by Bacillus spp. with occasional detection of Proteus spp., Acinetobacter spp. and Pseudomonas aeruginosa (Table 1).

On the floor, Staphylococcus spp. constituted $42.0 \%$ of the isolates and together with B. subtilis $(20.4 \%)$, they accounted for over $62 \%$. Among the Gram-negative bacterial isolates, $\mathrm{P}$. aeruginosa (13.0\%) and Proteus mirabilis (9.3\%) were the most prevalent. Other bacteria species isolated from the floor of the wards include Acinetobacter baumannii (5.6\%), Proteus monganii (1.9\%), Escherichia coli (3.7\%) and Salmonella arizonae (3.7\%).
Table 1: The distribution of the 121 bacteria isolated from the surgical wards of the hospital.

\begin{tabular}{lcc}
\hline Variables & $\begin{array}{c}\text { Air, } \\
\mathbf{n}(\%)\end{array}$ & $\begin{array}{c}\text { Floor, } \\
\mathbf{n}(\%)\end{array}$ \\
\hline Staphylococcus aureus & $37(55.2)$ & $12(22.2)$ \\
Staphylococcus epidermidis & $2(3.0)$ & $4(7.4)$ \\
Staphylococcus hyicus & $4(6.0)$ & $5(9.3)$ \\
Staphylococcus chromogenus & $2(3.0)$ & $2(3.7)$ \\
Bacillus subtilis & $13(19.4)$ & $11(20.4)$ \\
Proteus mirabilis & $6(99.0)$ & $5(9.3)$ \\
Proteus monganii & $0(0)$ & $1(1.9)$ \\
Escherichia coli & $1(1.5)$ & $2(3.7)$ \\
Acinetobacter baumanii & $1(1.49)$ & $3(5.6)$ \\
Pseudomonas aeruginosa & $1(1.49)$ & $7(13.0)$ \\
Salmonella arizonae & $0(0)$ & $2(3.7)$ \\
Total & $67(100)$ & $54(100)$ \\
\hline
\end{tabular}

In the air of the surgical wards, Staphylococcus spp. alone accounted for about $67 \%$ of the total isolates followed by Bacillus spp. (19.4\%). Proteus mirabilis (9.0\%) was the common Gramnegative bacteria.

Antimicrobial susceptibility testing results showed high level resistance against $\beta$-lactam class of antibiotics (Figures 1 and 2). An approximate $70 \%(33 / 47)$ and $65 \%(38 / 58)$ of the bacteria from the floor and air of the surgical wards, respectively, were resistant to penicillins.

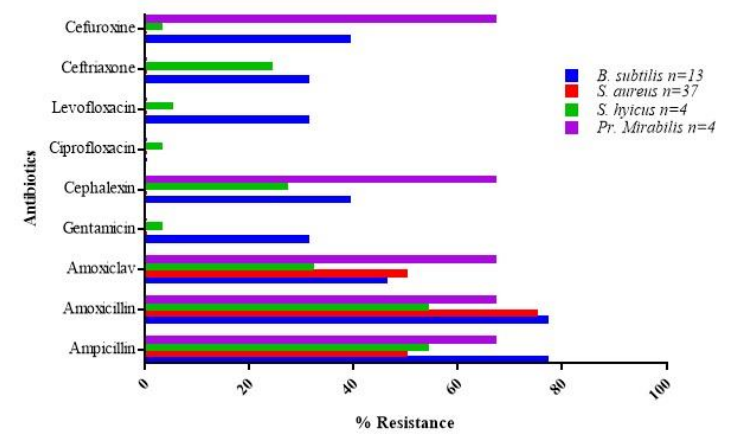

Figure 1. Antibiotic resistance profile of bacteria isolated from the air samples.

Some of the isolates such as $B$. subtilis, $P$. aeruginosa and $A$. baumannii exhibited $100 \%$ resistance to the penicillins. The resistance to cephalosporins was similarly high, particularly for the Gram-negative bacterial isolates. The isolates were however highly susceptible to 
fluoroquinolones with the exception of $B$. subtilis. Similarly, the isolates exhibited moderate to high level resistance to gentamicin.

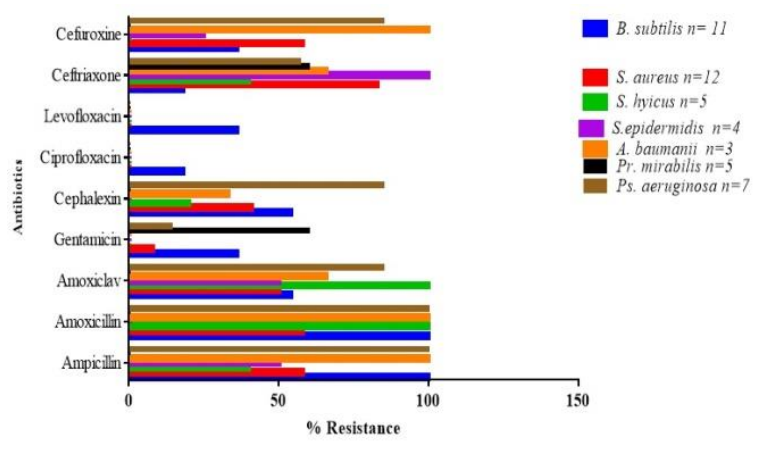

Figure 2. Antibiotic resistance profile of bacteria isolated from the floor samples.

\section{DISCUSSION}

The hospital environment is fairly stable microbiologically with the same set of bacteria isolated from the air and floor of the three surgical wards, day in, day out, from the beginning of the study to the end. This is in line with a previous report where the same set of bacterial species were isolated from different investigated hospital service units [16]. With the exception of Acinetobacter baumannii, our finding was consistent with the reports of similar studies at several university teaching hospitals in Nigeria $[8,17,18]$. A similar pattern of bacterial isolates has also been reported at the main oncology center in Sudan [19]. On the contrary, Micrococcus spp. and coagulase-negative staphylococci were the prevalent bacteria in the air of the surgical wards of two tertiary healthcare centers in Kano, Nigeria [20].

The higher rate of recovery bacterial isolates from the air $(55.4 \%)$ than the floor $(44.6 \%)$ of the hospital maybe due to the transmission of bacterial contaminants within the environment by the ventilation system and high human traffic within the wards.

It has been reported that, about $25 \%$ of hospital staff and significant proportion of in-patients are permanent carrier of $S$. aureus in their nostrils [22]. Expelled bacteria during rhinorrhea and sneezing may settle on surfaces. If surfaces are not properly cleaned or the bacteria resist the cleaning and disinfection then they may act as fomites which can be transmitted to patients by contact $[17,18,22]$. Staphylococcal species have been shown to harbour energy dependent multidrug resistant (MDR) efflux pump genes (qac $A / B$ and smr) conferring resistance to chlorhexidine, quaternary ammonium compounds and other biocides commonly used for disinfectant and antiseptic purpose in hospitals [22]. These findings underscore the urgent needs for evaluation of efficacy of the disinfectants being used in the hospital.

The high resistance of the isolates to the penicillins and cephalosporins antibiotics may suggest possible Extended Spectrum BetaLactamase-mediated resistance $[19,23]$. The occurrence of $\beta$-lactamase production among the bacterial isolates from the hospital environment has been well documented $[19,24,25]$.

Microbial quality of hospital environment is a major concern worldwide with regards to the safety and health of patients and hospitals staff. This has been shown to be an index of the level of hygienic condition of the hospital and a major risk factor for the occurrence of SSI $[17,26]$.

To further understand the health risk of the various environmental contaminants in the hospital, it is equally important to determine the load of the microbial contaminants present in the hospital environment. Regrettably, this was not done in this study. While pathogenic fungi have been shown in some studies to be major environmental contaminants in the surgical wards, its prevalence was not investigated in this study. Lastly, Genetic relatedness studies like multi-locus sequence typing and phylogenetic analysis could be carried out in future studies to establish that environmental isolates from air and floor of operating theatre and wards are the same as the ones causing nosocomial SSI in infected patients.

\section{Conclusion}

This study documents the diverse environmental microbiota of the surgical wards of the hospital. The resistance of the isolated bacteria to the commonly prescribed antibiotics in the hospital highlights the need for improved infection control and patient safety protocol in the hospital so as to mitigate the spread of nosocomial infections due to MDR pathogens in the surgical wards of the hospital.

\section{ACKNOWLEDGMENTS}


Contributions: All authors contributed equally in the conception, design, sample collection and analysis. The first draft of this manuscript was written by $O A$ which was critically reviewed and approved by all authors.

The authors gratefully acknowledged the technical assistance provided by the Department of Microbiology and Parasitology and the cooperation of the nursing staff in the Department of Surgery, University of Abuja Teaching Hospital, Gwagwalada, Abuja.

Declaration of Conflicting Interests: The authors declare that they have no conflict of interest.

Financial Disclosure: No financial support was received.

\section{REFERENCES}

1. Reichman DE, Greenberg JA. Reducing Surgical Site Infections: A Review. Rev Obstet Gyneacology 2009; 2:212-221.

2. Gottrup F, Melling A, Hollander DA. An Overview of Surgical Site Infections: Aetiology, Incidence and Risk Factors. EWMA J 2005; 5:11-15.

3. Berríos-Torres SI, Umscheid CA, Bratzler DW, et al. Centers for Disease Control and Prevention Guideline for the Prevention of Surgical Site Infection, 2017. JAMA Surg 2017; 152: 784-791.

4. Badri RM. Identification and Characterization of Bacteria Air Pathogens from Homes in Some Areas of the Baghdad City Material and Method: 2014; 2:384-388.

5. Nwankwo E. Isolation of pathogenic bacteria from fomites in the operating rooms of a specialist hospital in Kano, North-western Nigeria. Pak J Pharm Sci 2012; 12:90-96.

6. Poggio JL. Perioperative Strategies to Prevent Surgical-Site Infection. Clin Colon Rectal Surg 2013; $26: 168-73$

7. Nwankwo EO, Ibeh I, Enabulele OI. Incidence and risk factors of surgical site infection in a tertiary health institution in Kano, Northwestern Nigeria. Int J Infect Control 2012; 8:8-13.

8. Atata RF, Ibrahim YKE, Olurinola PF, Giwa A, Akanbi II AA, Sani AA. Clinical bacterial isolates from hospital environment as agents of surgical wound nosocomial infections. J Pharm Bioresour 2010; 7:146-55.

9. Onwubiko NE, Akande AO. Microbial Contamination In The Operating Theatre Of a Tertiary Health Institution In Kano, Northwestern Nigeria. Niger J Microbiol 1999;27:2671-2679.
10. Akanbi II AA, Kareem T, Adedoja A, et al. Bacterial contamination of medical doctors' white coats as contributing factor to hospital acquired infections. Int J Biol Chem Sci 2017; 11:185-194.

11. Nwankwo EO, Akande AO. Contaminated operating theatre foot wear: a potential source of healthcare associated infections in a northern Nigerian hospital. Int J Infect Control 2014; 11:611.

12. Famurewa O, David OM. Cell phone: A medium of transmission of bacterial pathogens. World Rural Obs 2009; 1:69-72.

13. Pathak A, Mahadik K, Swami MB, et al. Incidence and risk factors for surgical site infections in obstetric and gynecological surgeries from a teaching hospital in rural India. Antimicrob Resist Infect Control 2017; 6:66. doi:10.1186/s13756017-0223-y.

14. Napoli C, Marcotrigiano V, Montagna MT. Air sampling procedures to evaluate microbial contamination : a comparison between active and passive methods in operating theatres. BMC Public Health 2012; 12:1. doi:10.1186/1471-245812-594.

15. CLSI. Performance Standards for Antimicrobial Susceptibility Testing; Twenty-Fifth Informational Supplement. 2015.

16. Cabo Verde S, Almeida SM, Matos J, et al Microbiological assessment of indoor air quality at different hospital sites. Res Microbiol 2015; 166:557-563.

17. Obi C, Muhammad UK, Manga SB, Atata RF, Hauwa T. Assessment of commonly used Hospital Disinfectants on Bacteria isolated from the Operating Theatre. J Biosci Biotechnol Discov 2016; 1:59-65.

18. Shuaibu AS, Ibrahim YKE, Olayinka BO, et al. Phenotypic resistance of nosocomial bacterial isolates to some routinely used disinfectants. World J Pharm Med Res 2017; 3:52-56.

19. Nurain AM, Bilal NE, Ibrahim ME. The frequency and antimicrobial resistance patterns of nosocomial pathogens recovered from cancer patients and hospital environments. Asian Pac J Trop Biomed 2015; 5:1055-1059.

20. Nwankwo OE, Ejike N, Onyinyechi NP. Microbial contamination of air and protective wears in the operating theatre and surgical wards of two tertiary hospitals in Kano, Northwestern Nigeria. Int J Infect Control 2014; 11:1-9. doi:10.3396/IJIC.v11i3.020.15.

21. Monteiro A, Verde SC. Bacterial Bioburden in Hospital Environment. In: Viegas C., Viegas S., Gomes A., Täubel M., Sabino R. (eds) Exposure to Microbiological Agents in Indoor and Occupational Environments. Springer, Cham, 2017; p:321-328. doi:10.1007/978-3-319-61688-9. 
22. Kolmos HJ. Health Care Associated Infections: Sources and Routes of Transmission Microorganisms: Health care. Infect. Control, INTECH Open Access Publisher; 2012, p. 20-5. https://www.intechopen.com/books/infectioncontrol-updates/sources-and-routes-of-infection

23. Manyahi J. Bacteriological Spectrum of Post Operative Wound Infections And Their Antibiogram In A Tertiary Hospital, Dar Es Salaam, Tanzania. Muhimbili University of Health and Allied Sciences Muhimbili, 2012, http://ihi.eprints.org/1510/

24. Affifi M. Detection of Extended spectrum betalactamase producing Klebsiella pneumonia and Escherichia coli of environmental surfaces at upper Egypt. Int J Biol Chem 2013;7:58-68. doi:10.1186/s12879-015-1005-x.

25. Atata RF, Ibrahim YKE, Giwa A, Akanbi AA. Antibiotics resistance profile of bacterial isolates from surgical site and hospital environment in a University teaching hospital in Nigeria. J Med Med Sci 2013;4:181-187.

26. Hailemariam M, Birhaneselase M, Azerefege E. Bacterial load and antibiotic susceptibility pattern of isolates in operating rooms at Hawassa University Referral Hospital, southern Ethiopia. J Microbiol Antimicrob 2016; 8:1-6. doi:10.5897/JMA2015.0349. 